\title{
Upregulated sulfatase and downregulated MMP-3 in thoracic aortic aneurysm
}

\author{
Małgorzata Matusiewicz1,A-F, Maciej Rachwalik2,A-C,E,F, Małgorzata Krzystek-Korpacka, ${ }^{1, B, C, E, F}$, \\ Grzegorz Bielicki ${ }^{2, B, F}$, Izabela Berdowska ${ }^{1, C, E, F}$, Rafał Nowicki ${ }^{2, B, F}$, Andrzej Gamian ${ }^{1,3, A, E, F}$, Marek Jasiński ${ }^{2, C, E, F}$ \\ ${ }^{1}$ Department of Medical Biochemistry, Wroclaw Medical University, Poland \\ ${ }^{2}$ Department and Clinic of Cardiac Surgery, Wroclaw Medical University, Poland \\ ${ }^{3}$ Institute of Immunology and Experimental Therapy, Polish Academy of Sciences, Wrocław, Poland \\ A - research concept and design; $B$ - collection and/or assembly of data; $C$ - data analysis and interpretation; \\ $D$ - writing the article; $E$ - critical revision of the article; $F$ - final approval of the article
}

Address for correspondence

Małgorzata Matusiewicz

E-mail: malgorzata.matusiewicz@umed.wroc.pl

\section{Funding sources}

Research grant from Wroclaw Medical University, Poland (No. 1738).

\section{Conflict of interest}

None declared

Received on November 12, 2019

Reviewed on March 1, 2020

Accepted on March 21, 2020

Published online on May 18, 2020

Cite as

Matusiewicz M, Rachwalik M, Krzystek-Korpacka M, et al.

Upregulated sulfatase and downregulated MMP-3

in thoracic aortic aneurysm. Adv Clin Exp Med.

2020;29(5):565-572. doi:10.17219/acem/119383

DOI

10.17219/acem/119383

Copyright

Copyright by Author(s)

This is an article distributed under the terms of the

Creative Commons Attribution 3.0 Unported (CC BY 3.0)

(https://creativecommons.org/licenses/by/3.0/)

\begin{abstract}
Background. Thoracic aortic aneurysm (TAA) formation is accompanied by degradation of extracellular matrix components (EMC). Numerous matrix metalloproteinases (MMPs) have been implicated in the process, but the involvement of MMP-3 remains unclear. Additionally, the changes in proteoglycan (PG) structure can alter the signal transduction pathways in TAA, though the enzymatic systems which originate them are not fully understood.
\end{abstract}

Objectives. To measure MMP-3 and sulfatase levels in aneurysmal tissue, comparing them with nonaneurysmal vessels, and to investigate possible correlations with patients' serum levels in order to evaluate their potential usefulness in aiding aneurysm detection and monitoring.

Material and methods. The study included 74 patients (TAA: $n=42$; control group: $n=32$ ). Sulfatase activity was measured colometrically and MMP-3 levels were measured immunoenzymatically.

Results. Sulfatase activities were higher $(p=0.03)$ and MMP-3 concentrations lower $(p=0.014)$ in aneurysmal tissue than in normal aortic tissue. Medium-sized dilatations were associated with lower tissue MMP-3 concentrations than small dilatations ( $p=0.033$ ). No differences in sulfatase activity or MMP-3 concentration in the serum of TAA patients were observed in comparison with the controls. The serum and tissue levels of MMP-3 were correlated $(r=0.41 ; p<0.001)$. The serum levels of MMP-3 were significantly lower in the female patients than in the male patients $(p=0.006)$.

Conclusions. Our studies confirmed the lower MMP-3 levels in aneurysmal tissue, but the lack of a statistically confirmed reduction of MMP-3 in the blood serum seems to preclude its usefulness for diagnostic purposes. Our study points to the differences in MMP-3 behavior between TAA and abdominal aortic aneurysms. Significantly higher sulfatase activity in TAA tissue suggests a possible impact of sulfatase on signal transduction pathways involved in aneurysm formation.

Key words: metalloproteinases, ascending aortic aneurysm, matrix metalloproteinase-3, sulfatases, thoracic aortic aneurysm 


\section{Introduction}

Aortic aneurysms are localized dilatations of aorta exceeding 1.5 times its normal diameter, representing a loss of structural integrity of the vessels caused by changes in the composition of the extracellular matrix..$^{1-3}$ Tunica media, a middle layer of the aortic artery, contains elastin, collagen and smooth muscle cells (SMCs), as well as proteoglycans (PG) and glycoproteins; it is responsible for the mechanical properties of the aorta. ${ }^{1}$ When thinning of the arterial wall occurs, the pressure of the flowing blood causes dilatations of the artery, ultimately leading to a rupture. ${ }^{2}$ The thinning of the arterial wall is caused by degradation of the components of the extracellular matrix (ECM), mainly elastin, the degradation of which has been observed even in the early stages of aneurysm formation. ${ }^{3}$ The degradation of ECM components is primarily conducted by matrix metalloproteinases (MMPs).

Matrix metalloproteinases are a group of zinc-containing endopeptidases which exhibit similarities in structure and an ability to degrade the components of ECM, such as collagen and elastin. ${ }^{4}$ Numerous studies have been conducted to establish the role of MMPs in aneurysm formation. ${ }^{1,2}$ Upregulation of MMP-2 and MMP-9 has been confirmed by studies in animal models of aneurysm, in cell cultures and in humans. ${ }^{5-12}$ However, the data concerning MMP-3 is contradictory, and the role of this MMP in aneurysm formation remains unclear.

The MMP activity is under multilevel regulation involving, among other things, the presence of various growth factors. The availability of these growth factors depends on the composition of other elements of the ECM; i.e., PGs - and more precisely, on the state of their sulfation. By processing PG, sulfatases can enhance the level of certain growth factors, which in turn, through signal transduction, can enhance or inhibit the synthesis and activity of other enzymes, including MMPs. However, so far only limited studies have focused on this enzyme in connection to aneurysm formation. ${ }^{13}$

The prevalence of thoracic aortic aneurysm (TAA) in humans is increasing and is estimated to be around 4\%; however, the mortality rate due to ruptured aortas is around $80-95 \% .{ }^{14,15}$ In cases of elective surgery, the mortality rate decreases to $5-7 \% .{ }^{15}$ Thus, there is a need for screening procedures which would allow for early, noninvasive detection of the disease. A better understanding of the molecular background of TAA could aid in finding possible candidates for indicators of the disease. However, despite the breadth of research on TAA, not many studies to date have been undertaken to directly correlate tissue levels of enzymes with their systemic levels, which might be crucial in establishing such biomarkers.

Therefore, the goals of our study were to determine the levels of MMP-3 and sulfatase in aneurysmal tissue, comparing them with non-aneurysmal vessels, and to correlate these values to those measured in the serum of the same patients in order to evaluate their possible usefulness in aiding aneurysm detection and monitoring. We found that the concentrations of MMP-3 were downregulated in aneurysmal tissue, especially in medium-sized aneurysms, while the tissue activity of sulfatase was upregulated. Downregulation of MMP-3 might be a characteristic biochemical trait of TAA, distinguishing it from abdominal aneurysms in which MMP-3 upregulation has been observed. The differences in the serum levels of the 2 enzymes were not statistically significant, which seems to preclude their measurements for diagnostic purposes.

The study protocol was approved by the Medical Ethics Committee of Wroclaw Medical University, Poland, and written informed consent was obtained from the patients.

\section{Material and methods}

\section{Study population}

A group of 42 patients admitted for surgery due to TAA was enrolled into the study. Patients with stenosis or vulvar insufficiency $(n=32)$ served as a control group. There were 13 women and 29 men in the TAA group, and 10 women and 22 men in the control group $(\mathrm{p}=0.821)$. The mean age in the TAA group was 62 years $(95 \%$ confidence intervals $(95 \% \mathrm{CI})=$ $58-66)$ and 58 years (54-62) in the control group $(\mathrm{p}=0.167)$.

No patient in aneurysm group had a bicuspid aortic valve. The exclusion criteria also included the use of steroids or non-steroidal anti-inflammatory medication, or presence of malignancies of any type. Some of the patients were treated with angiotensin converting enzyme inhibitors (ACEIs) $(n=4), \beta$-adrenalytics $(n=11)$ or both $(n=10)$.

For analytical purposes, the patients were divided into subgroups according to aorta diameter: small $(\leq 3.9 \mathrm{~cm})$, medium-sized $(4.0-5.9 \mathrm{~cm})$ and large $(\geq 6.0 \mathrm{~cm})$.

\section{Material}

Aneurysmal fragments were collected during open-heart surgery and immediately frozen in liquid nitrogen and stored at $-80^{\circ} \mathrm{C}$ for further analysis. These aorta samples are usually dissected as a routine part of the operation and are discarded. Fragments from patients with normal-sized aortas were dissected into small strips $(5-7 \mathrm{~mm} \times 2 \mathrm{~cm})$. These harvestings did not interfere with the surgical closure of the aortotomy. Intraoperative photos of normal and ruptured aortas are presented in Fig. 1.

The tissue fragments were homogenized in $5 \mathrm{mM}$ of Tris$\mathrm{HCl}$ buffer (pH 7.0) using a FastPrep-24 homogenizer (MP Biomedicals, Solon, USA). Samples were subsequently centrifuged at $14,000 \times \mathrm{g}$ for $15 \mathrm{~min}$ and the supernatants were used for analysis. Blood samples were drawn with venous puncture in a fasting state. The serum samples were taken from clotted (30 min, room temperature) and centrifuged $(15 \mathrm{~min}, 1,500 \times \mathrm{g})$ blood. The samples were then stored at $-80^{\circ} \mathrm{C}$ until analysis. 

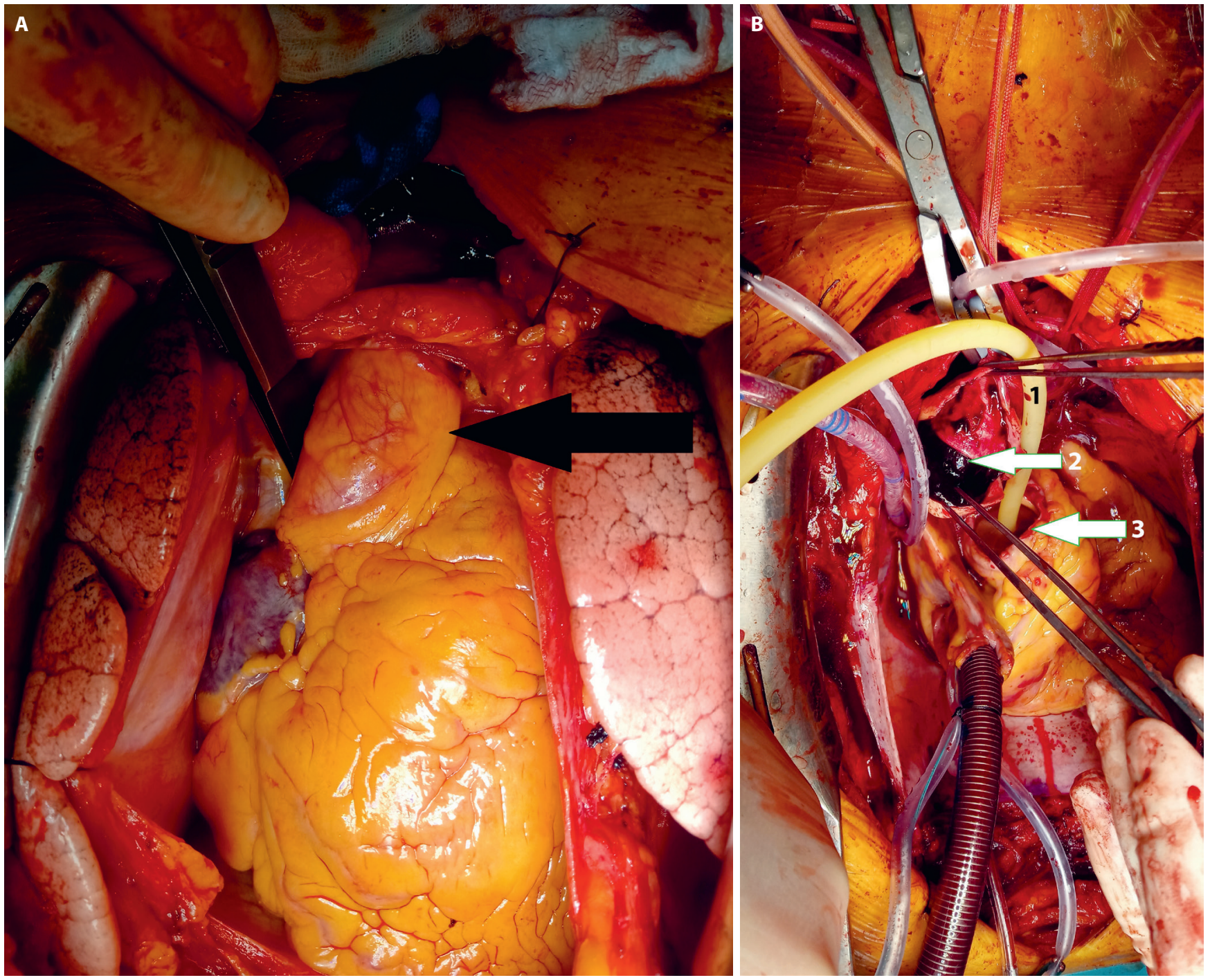

Fig. 1. A - normal-sized ascending aorta (black arrow), slightly elevated using surgical forceps; B - aortic dissection - intraoperative photo during the repair with cardiopulmonary bypass. Arrows indicate: 1 - false lumen of ruptured aortic aneurysm; 2 - true lumen of ruptured aortic aneurysm; 3 - foley catheter in true lumen of aortic aneurysm

\section{Analytical methods}

MMP-3

The MMP-3 concentrations were estimated using an enzyme double-antibody indirect immunoassay with Quantikine Human Total MMP-3 Immunoassay (R\&D Systems, Minneapolis, USA) in accordance with the manufacturer's protocol. The MMP-3 concentration in the serum samples is expressed as $\mathrm{ng} / \mathrm{mL}$ and in the homogenates as $\mathrm{ng} / \mathrm{g}$ of protein.

\section{Sulfatase}

Sulfatase activity was determined according to Singh et al., ${ }^{16}$ as all sulfatases in question display arylsulfatase activity. ${ }^{17}$ Briefly, equal aliquots of serum and substrate solution (20 mM of p-nitrocatechol sulfate (Sigma-Aldrich, St. Louis,
USA)) were incubated for $4 \mathrm{~h}$ at $37^{\circ} \mathrm{C}$ and the reaction was stopped with $2.5 \mathrm{M}$ of $\mathrm{NaOH}$. The serum and control samples were run in duplicate. Sulfatase activity unit (U) was calculated as nmol of p-nitrocatechol liberated per $1 \mathrm{~min}$ with $1 \mathrm{~L}$ of serum (or $1 \mathrm{~g}$ of protein in case of homogenates).

\section{Protein concentration}

The protein concentration of the tissue homogenates was estimated using the Bradford method (Pierce Coomassie Protein Assay Kit; Thermo Fisher Scientific, Rockford, USA). ${ }^{18}$

\section{Statistical analysis}

Data distribution was tested using Kolmogorov-Smirnov test and the homogeneity of variances was tested using Levene's test. The data is presented as means with 
95\% confidence intervals (95\% CI) and analyzed using the t-test for independent samples, with Welch correction for unequal variances if necessary or one-way analysis of variance (ANOVA) with Student-Neuman-Keuls's post hoc test. Correlation analysis was conducted using Pearson (r) and Spearman ( $\rho$ ) correlation tests. Frequency analysis was conducted using $X^{2}$ statistics. All calculated probabilities were two-tailed, and p-values $\leq 0.05$ were considered statistically significant. The analyses were performed using MedCalc ${ }^{\circledR}$ v. 12.1.1.0 statistical software (MedCalc Software, Mariakerke, Belgium).

\section{Results}

Sulfatase activity was significantly higher in the aneurysmal tissue than in the normal aortas (Fig. 2), with no difference between emergency and elective surgery ( $p=0.423$ ). Enzyme activity tended to be higher in the medium-sized aneurysms than in the small and large aneurysms (Table 1). Tissue activity did not correlate with gender $(\mathrm{p}=0.736)$.

In the case of serum sulfatase activity, the differences between the TAA patients and the controls were not statistically significant $(89.9 \mathrm{nmol} / \mathrm{L}(95 \% \mathrm{CI}=76-103)$ vs $79.9 \mathrm{nmol} / \mathrm{L}(95 \% \mathrm{CI}=69-91)$, respectively; $\mathrm{p}=0.240)$. Sulfatase activity in the serum tended to be higher among

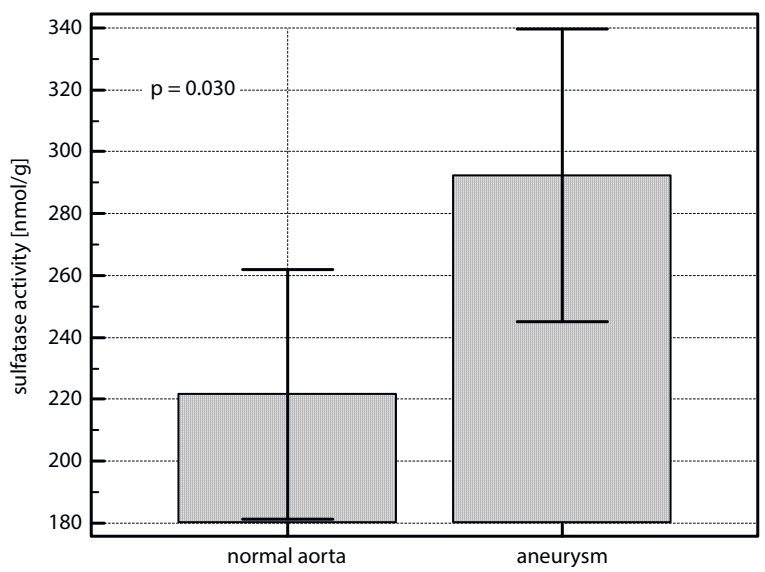

Fig. 2. Sulfatase activity in aneurysmal tissue $(n=42)$ and normal aorta $(n=32)$. Data is expressed as mean values with standard deviations (SD) women than men $(97.8 \mathrm{nmol} / \mathrm{L}(95 \% \mathrm{CI}=80-115)$ vs $80 \mathrm{nmol} / \mathrm{L}(95 \% \mathrm{CI}=70-90) ; \mathrm{p}=0.06)$. There was no correlation between the enzyme tissue and serum activity $(\mathrm{r}=0.11 ; \mathrm{p}=0.368)$.

The concentrations of MMP-3 were significantly lower in aneurysmal tissue than in tissue from normal aortas (Fig. 3), but did not differ with respect to urgency of surgery ( $\mathrm{p}=0.436$ ). Medium-sized aneurysms had lower concentrations of the enzyme than small aneurysms (Table 1). The differences in enzyme level in the serum between TAA patients and controls did not reach statistical significance $(6.6 \mathrm{ng} / \mathrm{mL}(95 \% \mathrm{CI}=5.4-7.8)$ vs $7.33 \mathrm{ng} / \mathrm{mL}(95 \%$ $\mathrm{CI}=6.3-8.4) ; \mathrm{p}=0.381)$. The MMP-3 serum levels were significantly lower in women than in men $(5.28 \mathrm{ng} / \mathrm{mL}(95 \%$ $\mathrm{CI}=3.9-6.7)$ vs $7.65 \mathrm{ng} / \mathrm{mL}(95 \% \mathrm{CI}=6.7-8.6) ; \mathrm{p}=0.006)$, while the tissue level of the enzyme did not correlate with gender $(p=0.627)$. The serum and tissue levels of the enzyme were correlated ( $\mathrm{r}=0.41$; $\mathrm{p}<0.001$; Fig. 4).

Serum MMP-3 and sulfatase levels tended to negatively correlate, particularly in the male subjects $(\mathrm{r}=-0.33$; $\mathrm{p}=0.026)$ or the control subjects $(\mathrm{r}=-0.41 ; \mathrm{p}=0.025)$. Tissue enzyme levels did not show any correlation.

Since some of our patients received treatment, we evaluated the effect of ACEIs and $\beta$-adrenalytics on the enzymes in question. Neither of the drugs had any influence on the levels of sulfatase or MMP-3 in the tissue. In the case

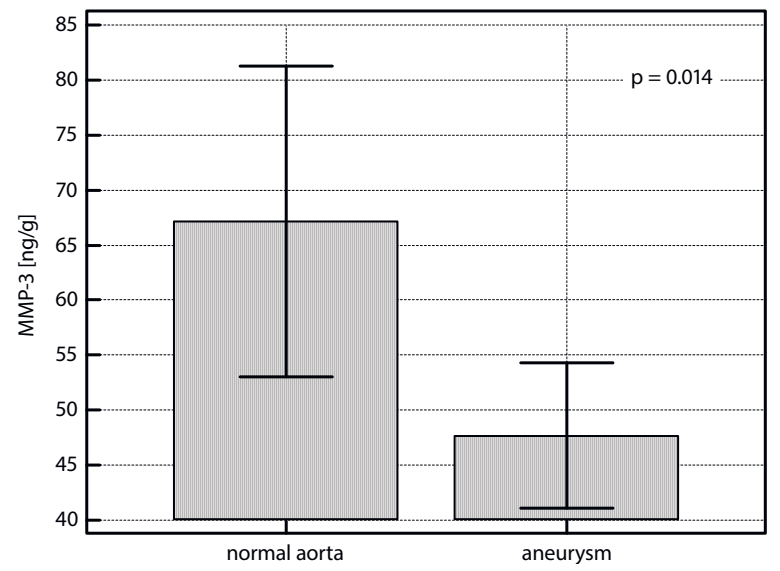

Fig. 3. MMP-3 concentration in aneurysmal tissue $(n=42)$ and normal aorta $(n=32)$. Data is expressed as mean values with standard deviations (SD)

Table 1. Sulfatase activity and MMP-3 concentration in relation to aorta diameter

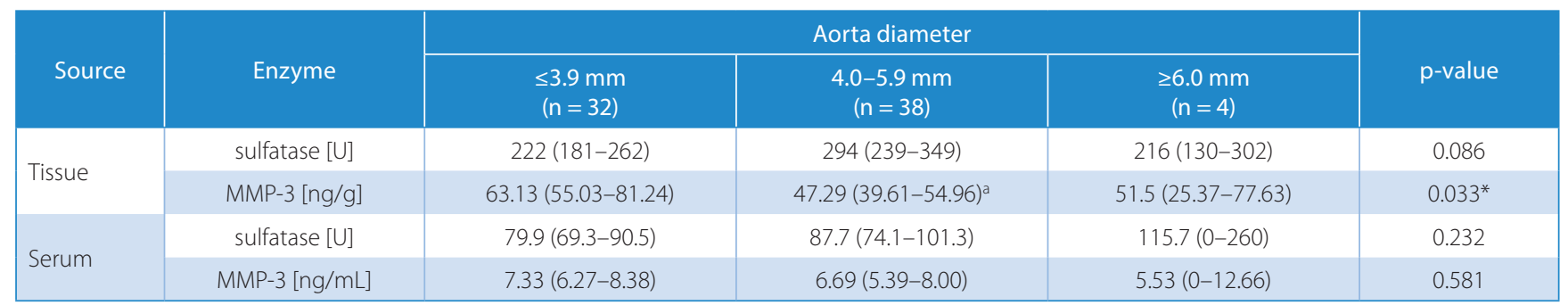

Data is presented as means with $95 \%$ confidence intervals ( $95 \% \mathrm{Cl}$ ) and was analyzed with one-way analysis of variance (ANOVA). ${ }^{*} \mathrm{p}$-values $\leq 0.05$ were considered statistically significant; ${ }^{a}$ statistically different from normal-sized aorta ( $\left.\leq 3.9 \mathrm{~mm}\right)$; MMP-3 - matrix metalloproteinase-3. 


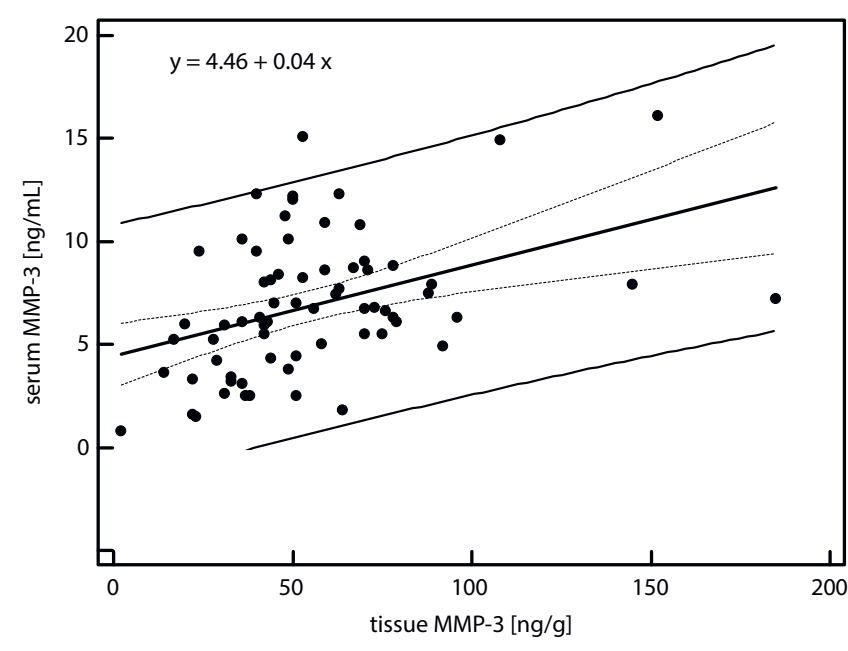

Fig. 4. The association between serum and tissue levels of matrix metalloproteinase-3 (MMP-3). Dashed regression line - 95\% confidence interval $(95 \% \mathrm{Cl})$; solid regression line - $95 \%$ prediction interval

of serum, neither ACEIs nor $\beta$-adrenalytics had an influence on MMP-3 levels. However, serum sulfatase activity was significantly higher among patients who were treated with ACEIs than among the untreated group ( $\mathrm{p}=0.015)$. When only patients without treatment were taken into consideration, there were no differences in serum sulfatase activity between the TAA and control groups ( $\mathrm{p}=0.878)$.

\section{Discussion}

The role of MMPs in the formation of aneurysms has been well documented. Conclusions have been drawn on the possible application of the findings of these studies in therapy and monitoring. However, it is impossible to directly measure the changes from the expression or activity of these enzymes in the affected tissue of a patient. Most of the studies on applying measurements of MMPs in the serum assume that tissue levels would be reflected on the systemic level, but there have been no studies to confirm this correlation so far. Therefore, our study was designed to measure the concentrations of one MMP - MMP-3 - in tissue fragments from aneurysmal and nonaneurysmal thoracic aortas and to correlate them with the serum levels of the same patients. To the best of our knowledge, our study is the first to demonstrate a direct correlation between tissue and serum levels of MMP-3. However, we also noted that despite the fact that MMP-3 was significantly lower in aneurysmal tissue, the differences in serum levels of the enzyme were not statistically significant.

The MMP-3, a stromelysin, is an enzyme whose role in aneurysm formation remains unclear. Apart from its direct role in the degradation of ECM elements, it also participates in the activation of other MMPs. ${ }^{4}$ Little is known about signal transduction pathways which might lie at the onset and development of aneurysm formation, but MMP-3 has been shown to cleave matrix components to release or activate various growth factors such as fibroblast growth factor (FGF), transforming growth factor- $\beta$ (TGF- $\beta$ ), heparin-binding epidermal growth factor (HB-EGF), or interleukin (IL)-1 $\beta .{ }^{19-21}$ Johnson et al. have recently demonstrated in their studies on MMP-3-knockout mice that MMP-3 is responsible for vascular SMC migration through MMP-9 activation and neointima formation. ${ }^{6}$ Earlier studies also implicated this MMP in the cleavage of E-cadherin, and thus in the promotion of cellular aggregation. ${ }^{22}$

Unlike MMP-2 and MMP-9, the upregulation of which has been almost unanimously demonstrated in numerous studies, ${ }^{5-12}$ the results coming from studies on MMP-3 are conflicting. Our study demonstrated decreased concentrations of MMP-3 in tissue homogenates from TAA, which is in agreement with a study by Ikonomidis et al. ${ }^{11}$ Using immunoblotting and zymography, they noted lower levels of MMP-3 in tissue homogenates from patients with TAA. At the same time, they did not observe the same phenomenon in tissues from patients with Marfan syndrome - an inherited autosomal disorder characterized by a higher susceptibility to aneurysm formation. In their subsequent studies, the researchers also confirmed the lower MMP-3 concentrations in aneurysmal tissues, but only in the case of medium-sized TAAs $(4.0-5.9 \mathrm{~cm}) .{ }^{23}$ These results have been further supported by the in vitro studies on primary murine fibroblasts from normal and induced TAA. ${ }^{24}$ The authors found not only different gene expressions in these 2 types of cells, but also phenotypic changes of fibroblasts during transformation from normal to aneurysmal tissue. However, these results are contradictory to data from a study on MMP-3-knockout mice, which exhibited reduced ascending and abdominal aortic aneurysm formation. ${ }^{25}$ Similarly, the only study so far to assess the serum concentration of MMP-3, conducted by Karapanagiotidis et al., has reported increased concentrations of this MMP in TAA in comparison to healthy subjects. ${ }^{26}$ Our research did not confirm their results - we observed a tendency towards lower MMP-3 serum concentrations in TAA patients. However, both studies indicated lower MMP-3 concentrations in women than in men. This fact may have influenced the results to a certain degree because Karapanagiotidis et al. included only 18 TAA patients -14 of which were men - and their control group consisted of 12 women and only 3 men, while in our study the proportions of men and women in the study groups were more balanced. In the literature, abdominal aortic aneurysms demonstrate more uniform upregulation of MMP-3, ${ }^{27,28}$ with the exception of a study by Patel et al., where MMP-3 was not detected in the SMCs from aneurysmal vessels. ${ }^{7}$ It is possible that the profiles of MMP-3 concentration during the formation of ascending and abdominal aortic aneurysms differ, since the molecular composition varies between ascending, descending and abdominal aortas - as it has already been established - and the mechanisms 
underlying aneurysm formation in these arteries can therefore involve different pathways ${ }^{1}$; this may explain the seemingly contradictory results in the studies on aneurysm. As has been recently reported, there are even differences in the patterns of MMP expression between TAA with and without a bicuspid valve. ${ }^{12}$ Our study group was uniform in this respect, since none of the patients had a bicuspid aortic valve.

The SMCs seem to play a central role in the degenerative processes of blood vessels. They change their phenotype depending on the surrounding environment, and these changes influence their synthetic and migratory properties. ${ }^{2,24}$ Aneurysmal tissue is characterized by fewer SMCs in the tunica media. ${ }^{3,29,30}$ Therefore, it can be hypothesized that even if SMC expression of MMP-3 stays at the same level, a smaller number of these cells in aneurysmal tissue would result in an overall decrease in the protein level of the enzyme. The reduction of MMP-3 activity might be explained by inhibition from the overexpressed tissue inhibitors of metalloproteinases (TIMP). However, in our studies we measured the protein level of MMP-3, not its activity; therefore, the reduction cannot be explained by increased inhibition from TIMPs, especially since the method we used in the study measures both free MMP-3 and MMP-3/TIMP complexes.

Another possible explanation for the discrepancies in the reported MMP-3 levels might be the stage of aneurysm formation. It has been demonstrated that medium-sized aneurysms $(4.0-5.9 \mathrm{~cm})$ exhibited lower levels of MMP-3, while small $(\leq 3.9 \mathrm{~cm})$ and large $(\geq 6 \mathrm{~cm})$ aneurysms did not differ from non-aneurysmal tissues in respect to the concentration of this enzyme. ${ }^{23}$ Our results partially corroborate these data - medium-sized aneurysms exhibited lower MMP-3 concentrations than small aneurysms. There was no statistical difference in MMP-3 concentration between large aneurysms and small or medium-sized aneurysms, which might be due to the small sample of large aneurysms in our study group. Further research monitoring the changes in aneurysm size, measured by ultrasound studies and MMP-3 concentration, might shed light on this problem. The positive correlation between tissue and serum levels which was established in this study indicates that measurements of serum MMP-3 concentration would reflect the changes of this MMP at the tissue level, but the lack of statistically confirmed differences between normal and TAA serum levels of this enzyme seems to imply that it is not suitable as a marker for diagnostic purposes. Nonetheless, this should be confirmed in larger-scale studies. Still, the downregulation of MMP-3 demonstrated by our and other studies seems to emerge as a characteristic molecular trait that distinguishes TAA from abdominal aortic aneurysm, in which upregulation of MMP-3 seems to be uniformly observed.

Collagen and elastin are responsible for the strength and elasticity of blood vessels, while the $3^{\text {rd }}$ element of ECM - PGs - maintain the integrity of the arterial wall, allow it to properly resist compressive forces, and serve as an anchor for a number of growth factors and regulators. ${ }^{31,32}$ The PGs are composed of a core protein to which glycosaminoglycan (GAG) chains are attached. Changes in the composition of GAGs have been observed in the degenerative processes of the cardiovascular system, including aneurysm. Theocharis et al. ${ }^{33}$ observed lower levels of heparan sulfate and chondroitin sulfate in abdominal aortic aneurysms in comparison to normal aortas. Their later studies indicated that aneurysmal tissue contains a reduced ratio of 6 -sulfate to 4-sulfate disaccharides. ${ }^{34}$ Moreover, while no changes in dermatan sulfate content have been noted, a decrease of oversulfated disaccharides - which are mainly present in this GAG - has been observed in aneurysmal tissue. The changes in composition and sulfation of PGs within the ECM has the potential to highly impact the structure and functioning of blood vessels. It has been documented that modulation of the fine structure of GAGs, including their sulfation, can influence signaling pathways. ${ }^{35,36}$ Three groups of enzymes have been implicated in the remodeling of heparan sulfate PGs. Cell surface PGs can be cleaved by MMPs, their heparan sulfate chains can be further cut by heparanase, and endosulfatases can remove 6-O sulfate groups from trisulfated disaccharides. ${ }^{36}$ The endosulfatases in question are a group of recently discovered extracellular enzymes which are able to remove sulfate groups from sulfate esters in ECM components. Since aneurysm formation is accompanied by a reduction in 6-sulfate GAGs, elevated levels of the enzymes responsible for sulfate group removal should be expected. We evaluated the activity of sulfatase and found that it was indeed significantly higher in the aneurysmal tissue as compared to normal tissue. To date, there has been only 1 other study indicating elevated sulfatase activity, though not in TAA but in abdominal aortic aneurysm. ${ }^{13}$ The elevation of sulfatase in aneurysmal tissue, reducing the sulfation of PGs, may cause impaired binding of growth factors stored by the ECM and may initiate signaling pathways other than those active in normal aortas. It has been demonstrated that heparan sulfate PGs mediate the binding between latent TGF- $\beta$-binding proteins (LTBP) and fibronectin. ${ }^{37}$ It is now believed that dysregulated TGF- $\beta$ signaling lies at the bottom of aneurysm formation. ${ }^{38}$ Alterations of TGF- $\beta$ signaling pathways have been demonstrated in a murine model for TAA. ${ }^{39}$ It has been further suggested that the altered TGF- $\beta$ signaling might stimulate TAA development by the induction of myofibroblast differentiation from the fibroblasts which are replacing SMCs undergoing apoptosis, and might thus contribute to the changes in ECM composition. ${ }^{3}$ The emergence of myofibroblasts has coincided with PG degradation. ${ }^{3}$ It can therefore be hypothesized that the decreased sulfation of PGs can lead, via disrupted binding of LTBP to the ECM elements, to the excessive production of active TGF- $\beta$, which in turn enters an alternative signaling pathway. However, it must also be noted that at this point 
it is unclear whether the differentiation of myofibroblasts is a factor which contributes to aneurysm progression or as a repair process, ${ }^{3}$ especially since it has also been suggested that the enhanced production of TGF- $\beta$ may play a protective role against aneurysm formation. ${ }^{40}$ Cheung et al. also proposed that alterations in the TGF- $\beta$ signaling pathway and activation of MMPs may be an option in the management of congenitally related aortopathy. ${ }^{10}$

Our studies demonstrated that sulfatase activity in the tissue was not reflected in serum levels. Moreover, we noted that administration of ACEIs might influence serum levels of this enzyme. These 2 factors seem to preclude the application of systemic sulfatase in diagnostic procedures. However, the observed differences in sulfatase activity between normal and aneurysmal aortas indicate the need for further studies, which might shed further light on the molecular basis of aneurysm formation.

\section{ORCID iDs}

Małgorzata Matusiewicz (1) https://orcid.org/0000-0003-4624-0109 Maciej Rachwalik (D) https://orcid.org/0000-0001-9714-4059 Małgorzata Krzystek-Korpacka (1) https://orcid.org/0000-0002-2753-8092 Grzegorz Bielicki (1) https://orcid.org/0000-0003-0888-4229 Izabela Berdowska (1) https://orcid.org/0000-0002-0275-4522 Rafał Nowicki (1) https://orcid.org/0000-0002-3256-552X

Andrzej Gamian (1) https://orcid.org/0000-0002-2206-6591 Marek Jasiński (1) https://orcid.org/0000-0002-9989-7748

\section{References}

1. Barbour JR, Spinale FG, Ikonomidis JS. Proteinase systems and thoracic aneurysm progression. J Surg Res. 2007;139(2):292-307.

2. Curci JA. Digging in the "soil" of the aorta to understand the growth of abdominal aortic aneurysms. Vascular. 2009;17(Suppl 1):S21-S21.

3. Jones JA, Beck C, Barbour JR, et al. Alterations in aortic cellular constituents during thoracic aortic aneurysm development: Myofibroblast-mediated vascular remodeling. Am J Pathol. 2009;175(4): 1746-1756.

4. Visse R, Nagase H. Matrix metalloproteinases and tissue inhibitors of metalloproteinases: Structure, function and biochemistry. Circ Res. 2003;92(8):827-839.

5. Johnson C, Galis ZS. Matrix metalloproteinase-2 and-9 differentially regulate smooth muscle cell migration and cell-mediated collagen organization. Arterioscler Thromb Vasc Biol. 2004;24:54-60.

6. Johnson JL, Dwivedi A, Somerville M, et al. Matrix metalloproteinase (MMP)-3 activates MMP-9 mediated vascular smooth muscle cell migration and neointima formation in mice. Arterioscler Thromb Vasc Biol. 2011;31(9):e35-e44.

7. Patel MI, Melrose JJ, Ghosh P, Appleberg M. Increased synthesis of matrix metalloproteinases by aortic smooth muscle cells is implicated in the etiopathogenesis of abdominal aortic aneurysms. J Vasc Surg. 1996;24(1):82-92.

8. Lesauskaite V, Tanganelli P, Sassi $C$, et al. Smooth muscle cells of the media in the dilatative pathology of ascending thoracic aorta: Morphology, immunoreactivity for osteopontin, matrix metalloproteinases, and their inhibitors. Hum Pathol. 2001;32(9):1003-1011.

9. Sinha I, Bethi S, Cronin P, et al. A biologic basis for asymmetric growth in descending thoracic aortic aneurysms: A role for matrix metalloproteinase 9 and 2. J Vasc Surg. 2006;43(2):342-348.

10. Cheung YF, Chow PC, So EK, Chan KW. Circulating transforming growth factor- $\beta$ and aortic dilation in patients with repaired congenital heart disease. Sci Rep. 2019;9(1):162. doi:10.1038/s41598-01836458-1

11. Ikonomidis JS, Jones JA, Barbour JR, et al. Expression of matrix metalloproteinases and endogenous inhibitors within ascending aortic aneurysms of patients with Marfan syndrome. Circulation. 2006; 114(Suppl 1):I-365-I-370.
12. Rabkin SW. Differential expression of MMP-2, MMP-9 and TIMP proteins in thoracic aortic aneurysm: Comparison with and without bicuspid aortic valve. A meta-analysis. Vasa. 2014;43(6):433-442.

13. Kowalewski R, Sobolewski K, Małkowski A, Wolańska M, Gacko M. Evaluation of enzymes involved in proteoglycans degradation in the wall of abdominal aortic aneurysms. J Vasc Res. 2006;43(1):95-100.

14. Lindholt JS, Juul S, Fasting $\mathrm{H}$, Henneberg EW. Screening for abdominal aortic aneurysms: Single-centre randomized controlled trial. BMJ. 2005;330(7494):750. doi:10.1136/bmj.38369.620162.82

15. Lindholt JS. Abdominal aortic aneurysms. Dan Med Bull. 2010;57: B4219.

16. Singh J, Tavella D, Di Ferrante N. Measurements of arylsulfatases $A$ and $B$ in human serum. J Pediatrics. 1975;86(4):574-576.

17. Morimoto-Tomita M, Uchimura K, Werb Z, et al. Cloning and characterization of two extracellular heparin-degrading endosulfatases in mice and humans. J Biol Chem. 2002;277(51):49175-49185.

18. Bradford MM. A rapid and sensitive method for the quantitation of microgram quantities of protein utilizing the principle of proteindye binding. Anal Biochem. 1976;72:248-254.

19. Whitelock JM, Murdoch AD, lozzo RV, Underwood PA. The degradation of human endothelial cell-derived perlecan and release of bound basic fibroblast growth factor by stromelysin, collagenase, plasmin, and heparanases. J Biol Chem. 1996;271(17):10079-10086.

20. Imai K, Hiramatsu A, Fukushima D, Pierschbacher MD, Okada Y. Degradation of decorin by matrix metalloproteinases: Identification of the cleavage sites, kinetic analyses and transforming growth factorbeta 1 release. Biochem J. 1997;322(Pt 3):809-814.

21. Suzuki M, Raab G, Moses MA, Fernandez CA, Klagsbrun M. Matrix metalloproteinase-3 releases active heparin-binding EGF-binding growth factor by cleavage at a specific juxtamembrane site. J Biol Chem. 1997;272(50):31730-31737.

22. Noe V, Fingleton $B$, Jacobs $K$, et al. Release of an invasion promoter E-cadherin fragment by matrilysin and stromelysin-1. J Cell Sci. 2001; 114(Pt 1):111-118.

23. Ikonomidis JS, Jones JA, Barbour JR, et al. Expression of matrix metalloproteinases and endogenous inhibitors within ascending aortic aneurysms of patients with bicuspid and tricuspid aortic valves. J Thorac Cardiovasc Surg. 2007;133(4):1028-1036.

24. Jones JA, Zavadzkas JA, Chang El, et al. Cellular phenotype transformation occurs during thoracic aortic aneurysm development. J Thorac Cardiovasc Surg. 2010;140(3):653-659.

25. Silence J, Lupu F, Collen D, Lijnen HR. Persistence of atherosclerotic plaque but reduced aneurysm formation in mice with stromelysin-1 (MMP-3) gene inactivation. Arterioscler Thromb Vasc Biol. 2001;21(9): 1140-1145.

26. Karapanagiotidis GT, Antonitsis P, Charokopos N, et al. Serum levels of matrix metalloproteinases-1,-2,-3 and -9 in thoracic aortic diseases and acute myocardial ischemia. J Cardiovasc Surg. 2009;4:59.

27. Carrel TWG, Burnand KG, Wells GMA, Clements JM, Smith A. Stromelysin-1 (matrix metalloproteinase-3) and tissue inhibitor of metalloproteinase-3 are overexpressed in the wall of abdominal aortic aneurysms. Circulation. 2002;105(4):477-482.

28. Hadi T, Boytard L, Silvestro M, et al. Macrophage-derived netrin-1 promotes abdominal aortic aneurysm formation by activating MMP3 in vascular smooth muscle cells. Nat Commun. 2018;9(1):5022. doi:10. 1038/s41467-018-07495-1

29. Della Corte A, Quarto C, Bancone C, et al. Spatiotemporal patterns of smooth muscle cell changes in ascending aortic dilatation with bicuspid and tricuspid aortic valve stenosis: Focus on cell-matrix signaling. J Thorac Cardiovasc Surg. 2008;135(1):8-18,e1-2.

30. Rowe VL, Stevens SL, Reddick TT, et al. Vascular smooth muscle cell apoptosis in aneurysmal, occlusive, and normal human aortas. J Vasc Surg. 2000;31(3):567-576.

31. Wight TN, Merrilees MJ. Proteoglycans in atherosclerosis and restenosis. Key roles for versican. Circ Res. 2004;94(9):1158-1167.

32. lozzo RV. The biology of small leucine-rich proteoglycans: Functional network of interactive proteins. J Biol Chem. 1999;274(27):1884318846.

33. Theocharis AD, Tsolakis I, Tsegenidis T, Karamanos NK. Human abdominal aortic aneurysm is closely associated with compositional and specific modifications at the glycosaminoglycan level. Atherosclerosis. 1999;145(2):359-368. 
34. Theocharis AD, Theocharis DA, De Luca G, Hjerpe A, Karamanos NK Compositional and structural alternations of chondroitin and dermatan sulfates during the progression of atherosclerosis and aneurismal dilatation of the human abdominal aorta. Biochimie. 2002;84(7): 667-674

35. Buono M, Cosma MP. Sulfatase activities towards the regulation of cell metabolism and signaling in mammals. Cell Mol Life Sci. 2010;67(5): 769-780.

36. Sanderson RD, Yang Y, Kelly T, MacLeod V, Dai Y, Theus A. Enzymatic remodeling of heparan sulfate proteoglycans within the tumor microenvironment: Growth regulation and the prospect of new cancer therapies. J Cell Biochem. 2005;96(5):897-905.
37. Chen Q, Sivakumar P, Barley C, et al. Potential role for heparan sulfate proteoglycans in regulation of transforming growth factor- $\beta$ (TGF- $\beta$ ) by modulating assembly of latent TGF- $\beta$-binding protein-1. J Biol Chem. 2007;282(36):26418-26430.

38. Powell JT, Länne T. Through thick and thin collagen fibrils, stress and aortic rupture: Another piece in the jigsaw. Circulation. 2007;115(21): 2687-2688.

39. Jones JA, Barbour JR, Stroud RE, et al. Altered transforming growth factor-beta signaling in a murine model of thoracic aortic aneurysm. J Vasc Res. 2008;45(6):457-468.

40. Wang $Y$, Ait-Oufelia H, Herbin O, et al. TGF- $\beta$ activity protects against inflammatory aortic aneurysm progression and complications in angiotensin II-infused mice. J Clin Invest. 2010;120(2):422-432. 